\section{JURNAL EKONOMI EFEKTIF}

ISSN : $2622-8882$, E-ISSN : 2622-9935

Jurnal Ekonomi Efektif, Vol. 4, No. 1, Oktober 2021 @Prodi Manajemen Fakultas Ekonomi Universitas Pamulang

\title{
PENGARUH KUALITAS PELAYANAN TERHADAP KEPUTUSAN PEMBELIAN KRISPY KREME DI SUPERMALL CILEDUG TANGERANG
}

\author{
Imam Sofyan Lubis ${ }^{1}$, Riyan Ardiansah ${ }^{2}$, Syukur Jaya ${ }^{3}$, Kasmad ${ }^{4 *}$ \\ Universitas Pamulang, Tangerang Selatan, Banten, Indonesia \\ imamsofyanlubis@gmail.com ${ }^{1}$, riyanardiansyah3012@gmail.com², \\ syukurjaya.laowo@gmail.com ${ }^{3}, \underline{\text { dosen00559@unpam.ac.id }{ }^{4 *}}$
}

Manuskrip: September -2021; Ditinjau: Oktober: -2021; Diterima: Oktober-2021; Online: Oktober-2021; Diterbitkan: Oktober-2021

\begin{abstract}
ABSTRAK
Penelitian ini bertujuan untuk mengetahui pengaruh kualitas pelayanan terhadap keputusan pembelian Krispy Kreme di Supermall Ciledug Tangerang. Metode yang digunakan adalah explanatory research dengan sampel sebanyak 96 responden. Teknik analisis menggunakan analisis statistik dengan pengujian regresi, korelasi, determinasi dan uji hipotesis. Hasil penelitian ini variabel kualitas pelayanan diperoleh nilai rata-rata skor sebesar 3,408 dengan kriteria baik. Variabel keputusan pembelian diperoleh nilai rata-rata skor sebesar 3,838 dengan kriteria baik. Kualitas pelayanan berpengaruh positif dan signifikan terhadap keputusan pembelian dengan nilai persamaan regresi $\mathrm{Y}=9,285+0,853 \mathrm{X}$, dan nilai koefisien korelasi 0,776 atau memiliki tingkat hubungan yang kuat dengan nilai determinasi 60,2\%. Uji hipotesis diperoleh signifikansi $0,000<0,05$.
\end{abstract}

\section{Kata Kunci: Kualitas Pelayanan, Keputusan Pembelian}

\section{ABSTRACT}

This study aims to determine the effect of service quality on purchasing decisions for Krispy Kreme at Supermall Ciledug Tangerang. The method used is explanatory research with a sample of 96 respondents. The analysis technique uses statistical analysis with regression, correlation, determination and hypothesis testing. The results of this study variable service quality obtained an average score of 3,408 with good criteria. The purchase decision variable obtained an average score of 3.838 with good criteria. Service quality has a positive and significant effect on purchasing decisions with a regression equation value of $Y=9.285+$ $0.853 X$, and a correlation coefficient of 0.776 or has a strong relationship with a determination value of $60.2 \%$. Hypothesis testing obtained a significance of $0.000<0.05$.

\section{Keywords: Service Quality, Purchase Decision}




\section{PENDAHULUAN}

\section{A. Latar Belakang Masalah}

Seiring perkembangan zaman dan gaya hidup, saat ini sudah banyak bermunculan cafe cafe dan menjadi tempat berkumpulnya anak anak muda, menghabiskan waktu luang nya, tak jarang juga banyak mahasiswa yang berkumpul selepas perkuliahan untuk mendapatkan tempat yang nyaman serta makanan dan minuman yang cocok untuk menemani kegiatan yang sedang dilakukan.

Di Indonesia sendiri, sudah banyak bermunculan berbagai macam bisnis dalam hampir di segala industri, baik industri manufaktur, industri food and beverages, restoran keluarga, café hingga counter penjualan yang hanya menyajikan minuman. Sebagai salah satu perusahaan Tbk yang terbesar, PT Mitra Adi Perkasa Tbk atau MAP memiliki pendapatan besar yang dihasilkan dari industri food and beverages, cafe dan restoran yang dimiliki oleh PT Mitra Adi Perkasa meiputi Starbucks, Krispy Kreme Doughnuts, Genki Sushi, Pizza Marzano, Cold Stone, Domino "es Pizza, Burger King, Paul Patisserie, dan Chatter Box. beberapa brand ini merupakan brand besar yang menjadi top of mind bagi masyarakat luas seperti starbucks, Krispy Kreme Doughnuts, dan Burger King salah satu brand cafe dan restoran milik PT Mitra Adi Perkasa yang ingin diteliti oleh penulis adalah Krispy Kreme Doughnuts.

Krispy Kreme Doughnuts adalah rumah makan siap saji yang menjual produk donat dan minuman. Dibuka di Winston-Salem, North California pada tangga 13 juli tahun 1937 oleh Vernon Rudolph. Di Indonesia sendiri Krispy Kreme Doughmuts di naungi oleh PT. Mitra Adi Perkasa. Krispy Kreme Doughnuts pertama kali dibuka di Indonesia pada tahun 2006 di mall senayan city dengan PT Mitra Adi Perkasa sebagai pemegang hak franchise dari Krispy Kreme Doughnuts Inc. Hingga tahun 2019, Krispy Kreme Doughnuts telah memiliki 35 cabang di Indonesia dan telah memiliki konsep toko sebagai café.

Namun, dalam dunia bisnis pasti sebuah perusahaan tidak dapat terhindar dari yang namanya persaingan di Indonesia sendiri industri food and beverages ternama yang menjual doughnuts dan kopi bukan hanya Krispy Kreme Doughnuts saja, melainkan ada Dunkin Donuts dan Jco kedua restoran tersebut tidak dapat dikatakan sebagai pesaing yang mudah karena keduanya juga memiliki reputasi yang kuat dan banyak nya cabang yang dimiliki lebih dari 35 cabang Krispy Kreme Dougnuts, kekurangan lainnya yang dimiliki oleh Krispy Kreme Doughnuts adalah harganya yang lebih mahal dibandingkan dari donat lain, yaitu Rp 12.000 per satuannya.

Untuk mengatasi persaingan ini, setiap restoran harus mempertahtikan berbagai macam faktor diantaranya, keputusan pembelian, kualitas produk dan kualitas pelayanan keputusan pembelian sendiri diartikan menurut Menurut Solomon (dalam Priansa, 2017) menyatakan bahwa keputusan pembelian adalah suatu perasaan keseluruhan konsumen mengenai produk atau jasa yang telah dibeli konsumen. Untuk menimbulkan keputusan pembelian, kualitas pelayanan menjadi hal yang sangat penting.

Krispy Kreme selalu berusaha memberikan pelayanan dengan baik di antaranya berusaha memberikan produk dengan mutu yang lebih baik, harga bersaing, penyerahan produk yang lebih cepat, fasilitas yang lebih memadai daripada pesaingnya. Karena pelayanan yang kurang baik dapat menimbulkan rasa tidak puas kepada konsumen dan pada akhirnya tidak akan menggunakan jasa pelayanan tersebut lagi. Cafe Krispy Kreme selalu berusaha meningkatkan kualitas pelayanannya agar bisa bersaing dengan para pesaingnya, namun usaha itu dikatakan belum berhasil karena pertumbuhan jumlah konsumen masih belum memuaskan perusahaan. 
Berdasarkan pada fenomena yang selama ini sering terjadi, secara eksplisit menunjukkan keputusan pembelian terutama dalam hal keputusan pembelian terhadap pelayanan dari pramusaji belum optimal. Sejatinya dalam usaha makanan dan minuman keramahan dari para pramusaji/pelayan adalah harga mati. Tidak jarang banyaknya konsumen yang datang dikarenakan pelayanan yang diberikan oleh pramusaji sangat baik. Hal ini menjadi pekerjaan rumah yang harus diselesaikan oleh Krispy Kreme dalam membangun keputusan pembelian.

Salah satu hal yang nyata kekurangan dari Krispy Kreme adalah konsistensi pramusaji dalam memberikan pelayanan yang ramah. Jika pada awal-awal pendirian seluruh karyawan begitu ramah dengan memberikan senyuman dan sapaan, namun saat ini ada sebagian karyawan yang kurang ramah. Tentunya hal ini berdampak pada prilaku konsumen yang bergeser dari nilai yang diharapkan.

Berdasarkan uraian di atas maka penulis tertarik melakukan penelitian dengan mengambil judul "Pengaruh Kualitas Pelayanan Terhadap Keputusan Pembelian Krispy Kreme Di Supermal Ciledug Tangerang".

\section{B. Rumusan Masalah}

1. Bagaimana kualitas pelayanan Krispy Kreme di Supermall Ciledug Tangerang ?.

2. Bagaimana keputusan pembelian Krispy Kreme di Supermall Ciledug Tangerang ?.

3. Adakah pengaruh antara kualitas pelayanan terhadap keputusan pembelian Krispy Kreme di Supermall Ciledug Tangerang ?.

\section{Tujuan Penelitian}

1. Untuk mengetahui kondisi kualitas pelayanan Krispy Kreme di Supermall Ciledug Tangerang.

2. Untuk mengetahui kondisi keputusan pembelian Krispy Kreme di Supermall Ciledug Tangerang.

3. Untuk mengetahui pengaruh kualitas pelayanan terhadap keputusan pembelian Krispy Kreme di Supermall Ciledug Tangerang.

\section{TINJAUAN PUSTAKA}

\section{Kualitas Pelayanan}

Menurut Kotler dalam Tjiptono (2019) menyatakan bahwa "Kualitas pelayanan adalah tingkat keunggulan yang diharapkan dan pengendalian atas tingkat keunggulan tersebut untuk memenuhi keinginan pelanggan".

\section{Keputusan Pembelian}

Menurut Kotler dan Amstrong (2019) berpendapat "perilaku konsumen merupakan sebuah pendekatan penyesuaian masalah yang terdiri dari lima tahap yang dilakukan konsumen. Kelima tahap tersebut adalah pengenalan masalah, pencarian informasi, evaluasi alternatif, keputusan pembelian, dan perilaku pasca pembelian”.

\section{METODE PENELITIAN}

\section{Populasi}

Yang dijadikan sebagai populasi dalam penelitian ini adalah responden yang berjumlah 96 responden yang membeli produk Krispy Kreme di Supermall Ciledug Tangerang

\section{Sampel}

Teknik pengambilan sampling dalam penelitian ini adalah sampel jenuh, dimana 
semua anggota populasi dijadikan sebagai sampel. Dengan demikian sampel dalam penelitian ini sampel yang digunakan berjumlah 96 responden.

\section{Jenis Penelitian}

Jenis penelitian yang dipakai adalah kuantitatif, dimana tujuannya adalah untuk mengetahui atau mencari keterhubungan antara variabel independen terhadap variabel dependennya

\section{Metode Analisis Data}

Dalam menganalisis data digunakan uji validitas, uji reliabilitas, analisis regresi linier sederhana, analisis koefisien korelasi, analisis koefisien determinasi dan pengujian hipotesis.

\section{HASIL PENELITIAN}

\section{Analisis Deskriptif}

Pada pengujian ini digunakan untuk mengetahui skor minimum dan maksimum skor tertinggi, ratting score dan standar deviasi dari masing-masing variabel. Adapun hasilnya sebagai berikut:

\section{Tabel 1. Hasil Analisis Descriptive Statistics}

Descriptive Statistics

\begin{tabular}{lr|r|r|r|r} 
& N & Minimum & Maximum & Mean & Std. Deviation \\
\hline Kualitas pelayanan (X) & 96 & 28 & 44 & 34.08 & 3.906 \\
\hline Keputusan Pembelian (Y) & 96 & 29 & 49 & 38.38 & 4.297 \\
\hline Valid N (listwise) & 96 & & & & \\
\hline
\end{tabular}

Kualitas pelayanan diperoleh varians minimum sebesar 28 dan varians maximum 44 dengan ratting score sebesar 3,408 dengan standar deviasi 3,906. Skor ini termasuk pada rentang sakala 3,40-4,19 dengan kriteria baik atau setuju.

Keputusan pembelian diperoleh varians minimum sebesar 29 dan varians maximum 49 dengan ratting score sebesar 3,838 dengan standar deviasi 4,297. Skor ini termasuk pada rentang sakala 3,40 - 4,19 dengan kriteria baik atau setuju.

\section{Analisis Kuantitatif}

Pada analisis ini dimaksudkan untuk mengetahui pengaruh variabel independen terhadap variabel dependen. Adapun hasil pengujian sebagai berikut:

\section{a. Analisis Regresi Linier Sederhana}

Uji regresi ini dimaksudkan untuk mengetahui perubahan variabel dependen jika variabel independen mengalami perubahan. Adapun hasil pengujiannya sebagai berikut:

\begin{tabular}{|c|c|c|c|c|c|c|}
\hline \multirow{3}{*}{\multicolumn{2}{|c|}{ Model }} & \multicolumn{3}{|c|}{ Coefficients $^{\mathrm{a}}$} & \multirow[b]{3}{*}{$\mathrm{t}$} & \multirow[b]{3}{*}{ Sig. } \\
\hline & & \multicolumn{2}{|c|}{$\begin{array}{l}\text { Unstandardized } \\
\text { Coefficients }\end{array}$} & \multirow{2}{*}{$\begin{array}{c}\text { Standardized } \\
\text { Coefficients } \\
\text { Beta }\end{array}$} & & \\
\hline & & $\mathrm{B}$ & Std. Error & & & \\
\hline 1 & (Constant) & 9.285 & 2.457 & & 3.779 & .000 \\
\hline & Kualitas Pelayanan (X) & .853 & .072 & .776 & 11.918 & .000 \\
\hline
\end{tabular}

a. Dependent Variable: Keputusan Pembelian (Y)

Berdasarkan hasil pengujian pada tabel di atas, diperoleh persamaan regresi $\mathrm{Y}$ $=9,285+0,853 \mathrm{X}$. Dari persamaan tersebut dijelaskan sebagai berikut:

1) Konstanta sebesar 9,285 diartikan jika kualitas pelayanan tidak ada, maka telah terdapat nilai keputusan pembelian sebesar 9,285 point.

2) Koefisien regresi kualitas pelayanan sebesar 0,853 , angka ini positif artinya setiap ada peningkatan kualitas pelayanan sebesar 0,853 point maka keputusan pembelian juga akan mengalami peningkatan sebesar 0,853 point. 


\section{b. Analisis Koefisien Korelasi}

Analisis koefisien korelasi dimaksudkan untuk mengetahui tingkat kekuatan hubungan dari variabel independen terhadap variabel dependen. Adapun hasil pengujian sebagai berikut:

Tabel 3. Hasil Pengujian Koefisien Korelasi Kualitas Pelayanan Terhadap Keputusan Pembelian.

\begin{tabular}{llrr} 
& \multicolumn{1}{c}{ Correlations $^{\mathbf{b}}$} & \multicolumn{1}{c}{$\begin{array}{c}\text { Kualitas } \\
\text { Pelayanan (X) }\end{array}$} & $\begin{array}{c}\text { Keputusan } \\
\text { Pembelian (Y) }\end{array}$ \\
\hline Kualitas Pelayanan (X) & Pearson Correlation & 1 & $.776^{* *}$ \\
\cline { 2 - 4 } & Sig. (2-tailed) & .000 \\
\hline Keputusan Pembelian (Y) & Pearson Correlation & $.776^{* *}$ & 1 \\
\cline { 2 - 4 } & Sig. (2-tailed) & .000 & \\
\hline
\end{tabular}

**. Correlation is significant at the 0.01 level (2-tailed).

b. Listwise $\mathrm{N}=96$

Berdasarkan hasil pengujian diperoleh nilai korelasi sebesar 0,776 artinya kualitas pelayanan memiliki hubungan yang kuat terhadap keputusan pembelian.

\section{c. Analisis Koefisien Determinasi}

Analisis koefisien determinasi dimaksudkan untuk mengetahui besarnya persentase pengaruh dari variabel independen terhadap variabel dependen. Adapun hasil pengujian sebagai berikut:

Tabel 4. Hasil Pengujian Koefisien Determinasi Kualitas Pelayanan Terhadap Keputusan Pembelian.

Model Summary

\begin{tabular}{l|l|c|cr} 
& & \multicolumn{2}{c}{} & \multicolumn{2}{c}{$\begin{array}{c}\text { Adjusted R } \\
\text { Model }\end{array}$} & R & R Square & \multicolumn{2}{c}{$\begin{array}{c}\text { Std. Error of the } \\
\text { Estimate }\end{array}$} \\
\hline 1 & $.776^{\mathrm{a}}$ & .602 & .598 & 2.726 \\
\hline
\end{tabular}

a. Predictors: (Constant), Kualitas Pelayanan (X)

Berdasarkan hasil pengujian diperoleh nilai determinasi sebesar 0,602 artinya kualitas pelayanan memiliki kontribusi pengaruh sebesar 60,2\% terhadap keputusan pembelian, sedangkan sisanya sebesar 39,2\% dipengaruhi oleh faktor lain yang tidak dilakukan penelitian.

\section{d. Uji Hipotesis}

Pengujian hipotesis dengan uji t digunakan untuk mengetahui hipotesis mana yang diterima.

Rumusan hipotesis: Terdapat pengaruh yang signifikan kualitas pelayanan terhadap keputusan pembelian.

Tabel 5. Hasil Uji Hipotesis Kualitas pelayanan Terhadap Keputusan Pembelian.

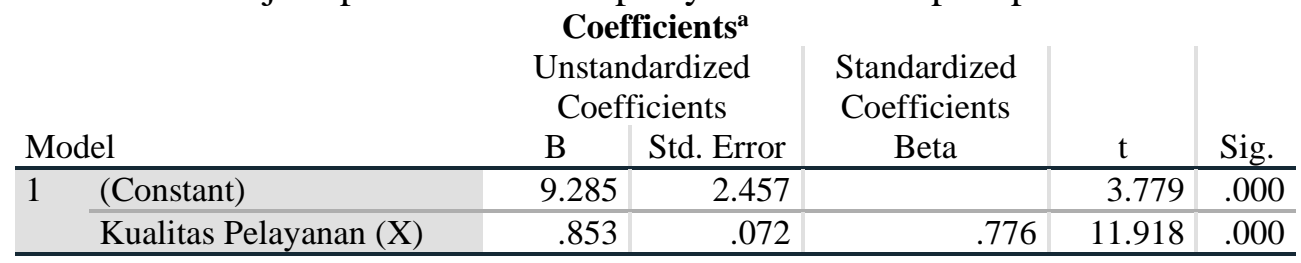

a. Dependent Variable: Keputusan Pembelian (Y)

Berdasarkan hasil pengujian pada tabel di atas, diperoleh nilai t hitung $>\mathrm{t}$ tabel atau $(11,918>1,986)$, dengan demikian hipotesis yang diajukan bahwa terdapat pengaruh yang signifikan atara kualitas pelayanan terhadap keputusan pembelian diterima. 


\section{Pembahasan Hasil Penelitian}

\section{Kondisi Jawaban Responden Variabel Kualitas Pelayanan}

Berdasarkan jawaban responden, variabel kualitas pelayanan diperoleh ratting score sebesar 3,408 berada di rentang skala 3,40 - 4,19 dengan kriteria baik atau setuju.

\section{Kondisi Jawaban Responden Variabel Keputusan Pembelian}

Berdasarkan jawaban responden, variabel keputusan pembelian diperoleh ratting score sebesar 3,838 berada di rentang skala 3,40 - 4,19 dengan kriteria baik atau setuju.

\section{Pengaruh Kualitas pelayanan Terhadap Keputusan Pembelian}

Kualitas pelayanan berpengaruh signifikan terhadap keputusan pembelian dengan persamaan regresi $\mathrm{Y}=9,285+0,853 \mathrm{X}$, nilai korelasi sebesar 0,776 atau memiliki hubungan yang kuat dengan kontribusi pengaruh sebesar 60,2\%. Pengujian hipotesis diperoleh nilai $t$ hitung $>\mathrm{t}$ tabel atau $(11,918>1,986)$. Dengan demikian hipotesis yang diajukan bahwa terdapat berpengaruh signifikan antara kualitas pelayanan terhadap keputusan pembelian diterima.

\section{KESIMPULAN DAN SARAN}

\section{Kesimpulan}

a. Variabel kualitas pelayanan diperoleh ratting score sebesar 3,408 berada di rentang skala 3,40 - 4,19 dengan kriteria baik atau setuju.

b. Variabel keputusan pembelian diperoleh ratting score sebesar 3,838 berada di rentang skala 3,40 - 4,19 dengan kriteria baik atau setuju.

c. Kualitas pelayanan berpengaruh signifikan terhadap keputusan pembelian dengan persamaan regresi $\mathrm{Y}=9,285+0,853 \mathrm{X}$, nilai korelasi sebesar 0,776 atau kuat dan kontribusi pengaruh sebesar 60,2\% sedangkan sisanya sebesar 39,2\% dipengaruhi faktor lain. Uji hipotesis diperoleh nilai t hitung $>\mathrm{t}$ tabel atau $(11,918>1,986)$.

\section{Saran}

Berdasarkan hasil penelitian di atas, maka penulis memberikan saran sebagai berikut:

a. Terkait pelayanan, perusahaan harus memberikan pelatihan kepada karyawannya khususnya cara melayani konsumen agar dapat berlaku lebih sopan, menghargai konsumen serta memahami cara menangani komplain konsumen.

b. Untuk mempengaruhi pembelian agar meningkat, perusahaan harus berupaya memenuhi keinginan konsumen serta harus memiliki banyak varian produk dan peningkatan mutu produk agar mampu memepuhi harapan konsumen

\section{DAFTAR PUSTAKA}

Algifari. (2015). “Analisis Regresi untuk Bisnis dan Ekonomi”. Yogyakarta: BPFE.

Arikunto, Suharsimi (2014). "Prosedur Penelitian Suatu Pendekatan Praktek”. Supermall Ciledug Tangerang: Rineka Cipta.

Bashu Swastha dan T. Handoko (2015) Manajemen Pemasaran Moderen, Yogyakarta: BPFE.

Basu Swastha Dharmmesta. (2014). Manajemen Pemasaran. BPFE: Yogyakarta. Buchari Alma. 2014. Manajemen pemasaran dan Pemasaran Jasa. Edisi Revisi.

Bilson Simamora (2016) Panduan Riset Prilaku Konsumen, Supermall Ciledug Tangerang: PT. Gramedia Pustaka. 
Erlangga, H., et al.(2021). Pengaruh Kualitas Pelayanan Dan Kualitas Produk Terhadap Keputusan Pembelian Konsumen Sepeda Motor Honda Di PT Panca Sakti Perkasa Di Bintaro. Jurnal Ilmiah PERKUSI, 1(4), 464-472.

Fandy Tjiptono (2017), Serivce Quality and Satisfiation. Supermall Ciledug Tangerang: Edisi tiga. Andi.

Freddy Rangkuti (2016) Strategi Promosi Yang Kreatif, Edisi Pertama, Cetakan Pertama Supermall Ciledug Tangerang: Gramedia Pustaka Utama.

Imam Ghozali (2017). “Aplikasi Analisis Multivariate Dengan Program SPSS”. Edisi Kelima. Semarang: Badan Penerbit Undip.

Istijanto (2014) "Riset Sumber Daya Manusia". Supermall Ciledug Tangerang: PT. Gramedia Pustaka

Kharis, Ismu Fadli (2011). "Studi Mengenai Impulse Buying dalam Penjualan Online”. Semarang : Skripsi Universitas Diponegoro

Kotler dan Amstrong (2017), Prinsip-prinsip Pemasaran. Edisi Kedua Belas”. Jilid Satu. Supermall Ciledug Tangerang: Erlangga.

Lupiyoadi (2016) Manajemen Pemasaran Jasa, Edisi 4, Supermall Ciledug Tangerang: Salemba Empat.

Mani, J. (2017). Pengaruh Persepsi Merek Dan Kualitas Pelayanan Terhadap Kepuasan Pelanggan (Studi Kasus Pada PT. Bisma Narendra Di Supermall Ciledug Tangerang). Jurnal Mandiri, 1(2), 187-206.

Nurjaya, N., et al. (2021). Pengaruh Brand Image Terhadap Keputusan Pembelian Pada PT. Wahana Motor Di Wilayah Cianjur. Jurnal Ilmiah PERKUSI, 1(2), 291-296.

Philip Kotler (2017) Manajemen Pemasaran, Edisi Keempat Belas, Supermall Ciledug Tangerang: PT. Indeks.

Phipil Kotler dan Kevin Keller (2017) Manajemen Pemasaran, Edisi Kedua Belas, Jilid Satu, Supermall Ciledug Tangerang: Erlangga.

Rao, Purba, (2012). "Measuring Consumer Perceptions Through Factor Analysis", The Asian.

Rasyid, N., et al. (2018). Pengaruh Bauran Pemasaran Terhadap Penjualan Pada PT. Nestle Indofood Citarasa Indonesia Di Makassar. SENTRALISASI, 7(2), 11-27.

Rofianto, W., et al. (2021). Cultural Product Branding, Antecedents, And Its Implications: A Study On The Context Of Indonesian Batik. International Journal Of Social, Policy And Law, 2(2), 37-46.

Santoso, Singgih (2015). "Menguasai Statistik Multivariat”. Supermall Ciledug Tangerang: PT Elex Media Komputindo.

Sudjana (2014) "Metode Statistika”, Bandung: Tarsido.

Sugiyono (2017), "Metode Penelitian Administrasi : dilengkapi dengan Metode $R \&$ D”. Bandung: Alfabeta.

Suhartanto (2014). “Metode Riset Pemasaran”. Bandung: Alfabeta 